\title{
Anterior Portion of the Urethra
}

National Cancer Institute

\section{Source}

National Cancer Institute. Anterior Portion of the Urethra. NCI Thesaurus. Code C61125.

The portion of the urethra that extends from the meatus to the membranous urethra. 